anthorities have adopted even this very primitive mode of classification, and it would give them but very little trouble and afford the best proof of the natural advantages and efficacy of the island as a health resort if they were to follow the classification of Dr. Farr or that of the Royal College of Physicians. It is evident that the authorities devote some degree of attention to vital statistics, and we would venture to invite their attention to the public health tables which are published monthly in THE LANCET as models upon which to frame their statistical tables. Such headings as "Infants-Different Diseases," "Senile Cachexia " are instances of a classification so indefinite as to render the statistics of little more use than the paper on which they are written.

(To be continued.)

\section{THE CHOLERA OUTBREAK IN TENERIFFE.}

\section{By H. Athill Cruttwell.}

(Continued from page 113.)

Continuing my description of this outbreak, it is of importance to note in further detail the nature and effects of the epidemic. At Teneriffe I found the place quiet in aspect, but by no means bearing a plague-stricken appearance; indeed, had I not known of the prevalence of cholera I should have been surprised to have been told of it, so little is the place changed from its usual appearance. The bay looks rather deserted, as, of course, the port is closed and most of the larger shops are shut, business being nearly at a standstill ; but people lounge about in fair numbers day and evening. The only typical signs of the visitation are the cleanliness-or rather, I should say, the comparative cleanliness - of the streets and the strewing of disinfectants at street corners and round infected houses. We have arrived at the end of the epidemic, which is now steadily subsiding; the panic is over, and I have no doubt that another fortnight or three weeks will see the end of it.

The death-rate throughout has been very low for cholera, only reaching a maximum of 26 per cent., and the cases have been almost entirely confined to the poorer and lower orders, scarcely any persons who are well-to-do having been attacked. The English, of whom there are fifty or so here, have escaped entirely. It is now two months and a half since the disease first appeared here, and there have been 264 deaths from it out of over 1000 cases. The highest number of deaths in one day, according to the official lists furnished $\mathrm{me}$, is 14 on the 25th ult, the highest number of new cases being 83 on the next day.

The following table gives the progress of the disease from day to day :-

\begin{tabular}{|c|c|c|c|c|c|c|c|c|c|c|c|}
\hline Dz & & Fres & & & eaths. & Da & & Fres & $\mathrm{BCa}$ & yes. & peatt \\
\hline Nov. & 1st & & - & $\cdots$ & 3 & Nov. & 27 th & $\ldots$. & 60 & & . 10 \\
\hline$"$ & 2nd & $\ldots$ & 2 & $\cdots$ & 4 & " & $28 \mathrm{th}$ & $\ldots$ & 72 & ....... & \\
\hline$"$ & $3 r d$ & & 3 & $\cdots$ & 1 & ", & 29 th & $\ldots$ & 76 & ......... & 10 \\
\hline$"$ & $\frac{4}{t h}$ & $\ldots$ & 1 & & 2 & & 30th & $\ldots$ & 74 & & \\
\hline " & 5th & $\ldots$ & 2 & …… & 1 & Dec. & 1st & $\cdots$ & 55 & $\cdots$ & \\
\hline " & 6 & $\cdots$ & $\frac{4}{2}$ & & 2 & $"$ & 2nd & $\cdots$ & 0 & & \\
\hline " & $\ln$ & $\cdots$ & $\begin{array}{l}3 \\
3 \\
3\end{array}$ & $\cdots \cdots \cdots$ & $\begin{array}{l}5 \\
3 \\
\end{array}$ & $"$ & $3 r d$ & . & 5 & $\cdots$ & 13 \\
\hline ", & $8 \mathrm{sen}$ & * & 3 & $\cdots \cdots \cdots$ & 3 & $"$ & 4 th & $\cdots$ & & & \\
\hline$"$ & $9 \mathrm{ch}$ & $\cdots$ & $\begin{array}{l}4 \\
8 \\
\end{array}$ & $\cdots$ & 4 & ", & 5 th & & & & \\
\hline$"$ & 10th & & 8 & $\cdots \cdots \cdots$ & 6 & $"$ & 6 th & $\cdots$ & 23 & $\cdots$ & \\
\hline$"$ & $10 \mathrm{th}$ & $\cdots$ & 10 & $\cdots$ & b & $"$ & 7 th & & 40 & & \\
\hline " & $12 t h$ & •* & 10 & $\cdots \cdots$ & 8 & $"$ & 8 th & $\ldots$ & & $\cdots$ & \\
\hline " & $13 \mathrm{Ln}$ & & 12 & $\cdots$ & 5 & $"$ & $95 \mathrm{~h}$ & $\cdots$ & 2 & & \\
\hline 3 & 1.th & & 15 & $\cdots$ & 71 & $"$ & $10 \mathrm{th}$ & $\ldots$ & & $\cdots$ & \\
\hline " & $\sin$ & $\ldots$ & 21 & $\cdots$ & 11 & " & 11th & $\cdots$ & 19 & & \\
\hline$" s$ & $=2+5$ & & 37 & …… & 5 & " & & $\cdots$ & & & \\
\hline$"$ & 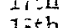 & & 87 & $\cdots$ & 6 & ", & 13 th & ... & 1 & & \\
\hline$\because$ & $10 \ln$ & & 80 & & & " & & ... & & & \\
\hline$"$ & lith & & $\begin{array}{l}20 \\
40\end{array}$ & & 6 & "g & 15 th & & 1 & & \\
\hline " & $20 t h$ & & 49 & -. & & $"$ & & $\ldots$ & & & \\
\hline " & $2 \mathrm{ls}$ & & hy & $\cdots$ & 12 & 3 & 17th & & 4 & & . \\
\hline & ?2na & & 40 & & 7 & & & & & & \\
\hline & $23 r$ & & 23 & & 8 & & 19 th & & & & \\
\hline$"$ & 2.th & & 59 & $\cdots$ & 8 & ", & 20 th & & 6 & & \\
\hline " & & & $5 ?$ & & 14 & $"$ & 21st & & 2 & & \\
\hline & & & 80 & & & & & & & & \\
\hline
\end{tabular}

The authorities are dealing with the outbreak in a fairly satisfactory manner; they have lately instituted a house-tolouse risitation, inquiring into the sanitation of each dwelling and rigorously destroying or disinfecting all infected cluthing, bedding, and furniture. This destruction of property tells kardly apon the poor, and, trade being paralysed, many men are out of employment, which adds considerably to the misery and want among them. To meet this a subscription was started, the Spanish Government giving $£ 200$, the Cable Company a like sum, while the merchants of all nationalities responded liberally. These funds have been used to provide food and clothing for those in actual need who are unable to work. Employment is found for able-bodied men in street cleaning, fumigating, \&c. I have been to one of the food-distributing centres in a poor quarter of the town. The building is a chapel turned for the nonce into a soup kitchen. Here was collected a crowd of women and children-the latter being very numerous-waiting for the distribution to begin. On a table in the centre of the nave was a large pile of loaves of bread, each weighing about balf a pound, and an enormous tin utensil full of a thick soup, the ingredients of which were rice, beans, lentils, and maize, served in meat stock. The allowance to each person is one loaf and a pint of soup twice a day, which is given to them on producing a ticket issued by one of the subcommittees of inquiry-for applications for assistance are looked into. The allowance is the same for children and adults, and it is a noticeable fact that the youngsters look healthy and fat. I doubt whether the majority of them have ever had so much food or of such good quality in their lives. Those I saw at the soup kitchen appeared to be healthy and happy. All were, of course, dirty -they always are so-but they were as far removed in bodily condition from the haggard, anxious folk to be seen at a London soup kitchen as possible, to judge from appearances. Of course here there is no bitter cold to contend with; children run about with nothing on but a shirt, or even naked; all are barefooted.

After leaving the soup kitchen I went to the lazaretto, to which all cases of cholera which cannot be properly isolated at home are removed. It is a long, narrow, high, stone building on the seashore just outside the town, surrounded by a wall on all sides, and looking, with its small barred windows and guarded gate, uncommonly like a prison. There are two long wards (male and female) in the main portion of the building, each being some $70 \mathrm{ft}$. long by $14 \mathrm{ft}$. high and each containing twenty-four beds. The male ward is on the lower floor, where I saw some twenty cases-nearly all children-but only one, an old man, in a really serious condition. The nurses are Roman Catholic Sisters, and these are assisted by a few men. I noticed that the place was built with good intentions as to ventilation, having five windows on either side, facing each other, at a height of nine or ten feet from the ground, so that currents of air could and should pass right across the room above the beds of patients and carry ofi heated and impure air. These windows were without exception closed, and not only closed, but the crevices were carefully sealed with strips of newspaper pasted over them; consequently, the only neans of ventilation were afforded by the door which opened at one end of the room from an ante-chamber communicating with the open courtyard. Needless to say, the atmosphere was foul. The bedclothes were far from clean; indeed, some were absolutely filthy, but the floor was passable. The only clean things in the place were the nun's coifs and aprons. 'This fetidity had attracted swarms of flies into the place, and it was pitiable to see the sick literally covered with these pests and impatiently waving their hands to drive them off. The old man I mentioned above was in a comatose state, and his face, neck, and arms were quite black with flies, which had even crept into his ears, nostrils, and open mouth, which was covered with crusted saliva. The walls were hung with sacred pictures, bad in design and gaudy in colour. At the end of the room opposite to the door a wooden stair-way led up to the female ward. This was a replica of the one below, but was very scantily filled with patients, most of whom, again, were children. Nearly all in the upper ward were convalescents

There is no resident medical man in the lazaretto, but as far as I can gather one calls in occasionally and irregularly, the Sisters of Mercy treating the sick during the intervals between the visits. One portion of the lazaretto is devoted to the fumigation of the clothing and bedding of patients. The method of sterilisation adopted is that of heat. There is a large metal chamber in the form of a cylinder connected with pipes for steam-carriage leading from a boiler. This chamber is some $8 \mathrm{ft}$. long by $5 \mathrm{ft}$. in diameter, and is fitted internally with a cot on wheels which run on tram lines. These lines are continued outside the chamber for a distance sufficient to allow the cot to be run out of it and filled 
with the articles to be sterilised. When filled the cot is run into the interior of the receptacle, the door hermetically secured by screw handles, and the steam turned on. On leaving the lazaretto I was disinfected by a spray of corrosive sublimate solution thrown all over me. There were about a dozen English visitors, all invalids, stranded here, unable to get away. They all look upon cholera as a matter of no importance, so far as they are concerned, but I can see that they will leave on the first opportunity. There is a burial law which provides that no bodies should be buried nntil they had been placed for twenty-four hours in the mortuary in a glass-faced coffin and watched by an attendant. Great difficulty was found in obtaining people to do this work until four bull-fighters, who were unable to leave the town, were employed to watch the cemetery and mortuary and to superintend the fumigations of infected houses. These posts, until the bull-fighters volunteered, the authorities were unable to fill.

We are cut off from the rest of the world in everything except mails, which are taken to Europe weekly by homeward bound ships going direct to England. The small vessel which brought me from Las Palmas calls from there weekly with mails and cargo, but takes hence mails only, and she is kept in the very strictest quarantine when lying off Las Palmas, where they are in terrible dread of cholera.

The towns and villages situated in other parts of the island have all, with the exception of Orotava, been visited with varying degrees of severity by cholera. Each town or village has surrounded itself by a cordon and all intercommunication is rigidly suspended, the state of panic inland being greater than it has been here. Orotava is the chief resort of invalids from Europe and they have been specially strict about the possibilities of infection. The season in Teneriffe, it is needless to say, has been wellnigh ruined.

The epidemic has now died out, but a few quotations from the official figures will serve to indicate its course and severity. From the middle (15th) of November to the end (7th) of the first week in December the average number of new cases daily was $42 \cdot 75$ and the average daily death-rate from cholera 7.9. From this date onwards the number of new cases at first gradually and at last rapidly declined. Since Dec. 19th only 2 deaths have occurred, and there have been no fresh cases since the 22nd of the same month.

\section{VITAL STATISTICS.}

HEALTH OF ENGLISF TOWNS.

IN thirty-three of the largest English towns 6755 births and 4654 deaths were registered during the week ending Jan. 20th. The annual rate of mortality in these towns, which had increased from 22.6 to 28.6 per 1000 in the preceding three weeks, declined last week to '23.2. In London the rate was 23.7 per 1000, while it averaged 22.9 in the thirty-two provincial towns. The lowest rates in these towns were 152 in Halifax, 15.7 in Leicester, 16.3 in Croydon, 16.5 in Portsmouth, and 16.9 in Oldham; the highest rates were 26.9 in Derby, 28.3 in Bristol, 29.9 in Birmingham, 38.0 in Plymouth, and 42.4 in Norwich. The 4654 deaths included 497 which were referred to the principal zymotic diseases, against 496 and 548 in the preceding two weeks ; of these, 194 resulted from whoopingcough, 84 from measles, 74 from diphtheria, 46 from scarlet fever, 43 from "fever" (principally enteric) 40 from diarrhoea, and 16 from small-pox. No fatal case of any of these diseases occurred last week in Norwich; in the other towns they caused the lowest death-rates in Leicester, Portsmouth, Brighton, and Derby and the highest rates in Bristol, Bolton, Salford, Plymouth, and Birkenhead. The greatest mortality from measles occurred in Wolverhampton, Salford, and Birkenhead; from scarlet fever in Burnley and Huddersfield; from whoopingcough in Bristol, Cardiff, Croydon, Sallord, Bolton, and Plymouth ; and from "fever" in Sunderland. The 74 deaths from diphtheria included 48 in London, 4 in Salford, and 3 each in Birmingham, Liverpool, Leeds, and Sheffield. Six fatal cases of small-pox were registered in Birmingham, 4 in Bradford, 3 in Bristol, and 1 each in West Ham, Leeds, and Hull, but not one in London or in any other of the thirtythree large towns. There were 82 cases of small-pox under treatment in the Metropolitan Asylum Hospitals and in the Highgate Small-pox Hospital on Saturday last, the 20th inst, against 93, 94, ard 88 at the end of the preceding three weeks; 14 new cases were admitted during the week against 15 and 12 in the preceding two weeks. The number of scarlet fever patients in the Metropolitan Asylums Hospitals and in the London Fever Hospital at the end of the week was 2645 , against 2988,2855 , and 2736 on the preceding three Saturdays ; 246 new cases were admitted during the week, against 210 and 224 in the preceding two weeks. The deaths referred to diseases of the respiratory organs in London, which had been 566 and 762 in the preceding two weeks, declined again to 547 last week, and were 198 above the corrected average. The causes of 72 , or 0.5 per cent., of the deaths in the thirty-three towns were not certified either by a registered medical practitioner or by a coroner. All the causes of death were duly certified in Leicester. Nottingham, Bradford, Newcastle-on-Tyne, and in ten other smaller towns; the largest proportions of uncertified deaths were registered in West Ham, Birmingham, Halifax, and Hull.

\section{HEALTH OF SCOTCH TOWNS.}

The annual rate of mortality in the eight Scotch towns, which had been 21.5 and 23.8 per 1000 in the preceding two weeks, declined again to $21 \cdot 6$ during the week ending Jan. $20 \mathrm{th}$, and was 1.6 per 1000 below the mean rate during the same period in the thirty-three large English towns. The rates in the eight Scotch towns ranged from 12.5 in Greenock and 194 in Aberdeen to 27.4 in Perth, and 34.7 in Paisley. The 616 deaths in these towns included 24 which were re. ferred to whooping-cough, 13 to diphtheria, 9 to scarlet fever, 5 to diarrhoea, 5 to "fever"; 2 to small-pox, and 1 to measles. In all, 59 deaths resulted from these principal zymotic diseases, against 76 in each of the preceding two weeks. These 59 deaths were equal to an annual rate of 2 ? per 1000 , which was 0.4 below the mean rate last week from the same diseases in the thirty-three large English towns. The fatal cases of whooping-cough, which had increased from 27 to 48 in the preceding four weeks, declined again to 24 last week, of which 13 occurred in Glasgow, and 4 in Dundee. The deaths referred to diphtheria, which had been 12 and 8 in the preceding two weeks, rose again to 13 last week, and included 6 in Glasgow, 2 in Dundee, and 2 in Leith. The 9 fatal cases of scarlet fever exceeded by 4 the number in the preced. ing week, and included 5 in Glasgow, and 3 in Edinburgh. of the 5 deaths referred to different forms of "fever" 4 were recorded in Glasgow. The 2 fatal cases of small-pox were registered in Leith. The deaths referred to diseases of the respiratory organs in these towns, which had been 146 and 157 in the preceding two weeks, declined to 150 last week, and were 77 below the number in the corresponding week of last year. The causes of 34 , or nearly 6 per cent., of the deaths in these eight towns last week were not certified.

\section{HEALTH OF DUBLIN.}

The death-rate in Dublin, which had been 27.1 and 42.5 per 1000 in the preceding two weeks, declined again to 30.9 during the week ending Jan. 20th. During the past three weeks of the current quarter the death-rate in the city has averaged 33.5 per 1000 , against 259 in London and 203 in Ninburgh. The 207 deaths registered in Dublin during the week under notice showed a decline of 78 from the number in the preceding week, and included 25 which were referred to the principal zymotic diseases, against 13 and 21 in the preceding two weeks ; of these 25 deaths, 12 resulted from whooping-cough, 5 from "fever," 4 from diarrhoea, 3 from measles, 1 from diphtheria, and not one either from smallpox or scarlet fever. These 25 deaths were equal to an annual rate of 3.7 per 1000 , the zymotic death-rate during the same period being 2.9 in London and 1.2 in Edinburgh. The fatal cases of whooping-cough, which had been 5 and 6 in the preceding two weeks, further rose to 12 last week, a higher number than in any week since March, 1886. The deaths referred to different forms of "fever," which had been 2 and 4 in the preceding two weeks, further increased to 5 last week. The 3 fatal cases of measles showed a decline of 4 from the number in the preceding week. The 207 deaths registered in Dublin last week included 38 of infants under one year of age, and 58 of persons aged upwards of sixty years ; the deaths both of infants and of elderly persons showed a decline from the high numbers recorded in the preceding week. Eight inquest cases and 7 deaths from violence were registered; and 59, or more than a fourth, of the deaths occurred in public institutions. The causes of 22 , or nearly 11 per cent., of the deaths in the city last weet were not certified. 